\title{
Emotional disorders in evolutionary perspective
}

\author{
Randolph Nesse* \\ Room 5057 I.S.R., The University of Michigan, 426 Thompson Stret, Ann Arbor, \\ MI 48106-1248, USA
}

\begin{abstract}
Understanding emotional disorders requires understanding the evolutionary origins and functions of normal emotions. They ate special states, shaped by natural selection to adjust various aspects of the organism in ways that have tended to give a selective advantage in the face of the adaptive challenges characteristic of a particular kind of situation. They are designed to maximize reproductive success, not happiness. Negative emotions such as anxiety and low mood are not disorders, but, like the capacity for pain, evolved defences. Excessive anxiety or low mood is abnormal, but we will not have confidence about what is excessive until we understand their functions better than we do. Emotional disorders arise often from social emotions because of the conflicts inherent in social life, and because of the strategic advantages of demonstrating commitments to follow through on threats and promises. An evolutionary understanding of individuals in terms of their relationship strategies and the social emotions offers great promise for psychotherapists.
\end{abstract}

Most psychological disorders are emotional disorders and most emotional disorders arise in situations of social conflict. Thus, thoughtful psychiatrists and clinical psychologists spend much effort trying to understand the interconnections between a person's feelings and relationships. The enterprise is difficult, in part, because social emotions are often vastly more complex and intense than seems sensible. Some people fly into rages at minor slights and others experience infatuation that persists for years, preventing new relationships. Couples sometimes spend most of their emotional energy on fighting. Parents who lose a child can become so distraught that they neglect other children. Some people are desperate for love, but viciously attack anyone who offers them a real relationship. And then there are the people who influence others by threatening to kill themselves. Much of this excess seems senseless. Why isn't the organism designed to simply assess a situation and then act on the best option? Why is social emotion so often excessively emotional? Wouldn't people be better off if they were just more rational? The answers to these questions have obvious major implications not just for treating psychopathology, but also for understanding social life more generally.

This paper begins by addressing how natural selection is likely to have shaped emotions and how evolutionary hypotheses about emotions can be tested. A summary of the origins and functions of the instrumental emotions is followed by a section on the clinical importance of recognizing the utility of negative emotions including anxiety, low mood and depression. The several benefits of social behaviour are then presented as preparation for more detailed discussions of attachment, reciprocity and the moral

* Requests for reprints (e-mail: nesse@umich.edu). 
passions. Finally, principles from game theory are applied to the social emotions to help explain why they often are so intense and apparently irrational. The clinical and research significance of this evolutionary perspective on emotions is reviewed in each section.

\section{Emotions in evolutionary perspective}

There is a long tradition in psychology of studying the 'functions' of emotions, and how they facilitate 'adaptation' that is not based on biology. In this tradition, 'function' and 'adaptation' usually refer to the individual's adjustment to a social setting. In biology, however, adaptations are traits shaped by natural selection that serve functions that increase net reproductive success (Williams, 1966). Of the growing body of work on emotions that is based on evolutionary biology, much of it confounds explanations based on how selective forces have shaped an emotion with explanations based on phylogenetic continuity. Of studies that do seek explanations based on how natural selection has shaped the emotional capacities, many are based on outmoded ideas such as group selection, or they confound questions about individual differences with questions about the generic design of the organism, or they are based on vague statements about the general benefits of emotional states, such as happiness, that are purported to be more beneficial than other states. Most emotions researchers now agree that an evolutionary foundation is essential for their work, but major disagreements persist about what that means and how to do it (Plutchik \& Kellerman, 1980).

A systematic approach to the evolution of the emotions is developing, based on explicit attention to how they were shaped by natural selection (Nesse, 1990a; Tooby \& Cosmides, 1990). The core idea is that certain specific kinds of situations with major adaptive challenges arose frequently in the course of evolution, and individuals with a genetic tendency to adjust various parameters to the needs of those situations had an increased ability to cope that gave increased reproductive success. In this perspective, the emotions are analogous to computer programs that take over the operation of many aspects of the system to improve the ability to deal with specific adaptive challenges. Just as the computer user faces different challenges when the task is word processing, as compared to drawing, database searching or doing statistics, an organism faces different challenges in situations where a food bonanza is available, as compared to a predator, dealing with a status challenge, or a mating opportunity. Certain situations seem to have recurred often enough in the course of evolution, and have had enough impact on fitness, to shape special emotional states.

This perspective collapses some traditional problems in emotions research (Ekman \& Davidson, 1994). The question of which aspect of emotions is primary-cognition, physiology, behaviour or subjective experience-becomes a non-issue. In a particular situation, a variety of aspects of the organism change in concert. (Cognitive assessment of the adaptive significance of a situation usually initiates an emotion, but secondary cognitive changes are just one aspect of the emotional state.) Similarly, questions about which function of an emotion is most important are clarified. An emotion can give advantages by communication, motivation, changes in cognition or physiology, or influences on current or future behaviour. Thus, explanations of emotions based on one function are inherently limited. The question of whether there are basic emotions, and how many there are, also becomes more clear on recognition that natural selection would 
usually shape new special states of arousal from preexisting states, and would differentiate them to the extent that this offers incremental benefits. Thus, we should expect different emotional states to be partly differentiated and partly overlapping, in both their characteristics and their regulation, with relatively specific states for distinct situations of great impact to fitness where specific adjustments give major benefits, and less distinctly different states for situations that are more complex or for which the optimal settings for the organism are less well-defined. The questions of why emotions have positive or negative valence, and why there seem to be more distinct negative than positive emotions are also illuminated. A situation that did not present risks or opportunities would not shape a special state, so all emotions have a valence. For most organisms, only a few kinds of situations offer opportunities, while many different situations pose distinct risks, so there are more different kinds of negative than positive emotions.

This perspective also offers some suggestions about how to go about defining and testing hypotheses about the evolutionary functions of emotions. The most important implication is that an explanation cannot be found in the aspects of the emotion alone. One cannot offer an evolutionary explanation for fear in the benefits of high heart rate or seeking escape or freezing, except insofar as those characteristics increase the ability to cope with the demands of a specific situation. An evolutionary explanation for an emotion is not to be found in the characteristics of either the emotion or the situation, but only in their interface-how the characteristics of the emotion give a selective advantage in the face of the adaptive challenges of a particular situation. Thus, any hypothesis about the evolutionary utility of an emotion must be grounded in a very explicit description of the situation in which the emotion is thought to be useful and the selective forces in that situation. The test of the hypothesis then depends on whether the regulation of the emotion is indeed designed to arouse the emotion in that situation, and whether the aspects of the emotion do indeed increase the ability to deal with the selective forces that arise in that situation (N esse, 1990a).

The starting point for matching emotions to corresponding situations is usually the observed emotions. Here, however, we will start with those situations that can be expected to have shaped specific emotions because they involve a gain or loss of reproductive resources (such as health, abilities, property, a mate, children, other kin, friends, reputation, status, friends or group membership). Situations that involve loss or a threat of loss of a reproductive resource are good candidates for shaping distinct negative emotional states. Situations that involve gain or potential gain of these resources are good candidates for shaping positive emotional states. Broad classifications of emotions al ong these lines go back to A ristotle, were developed by Aquinas and made especially explicit by Hume and Hobbes. A table (Table 1) showing this evolutionary approach may make the relationships of these basic emotions to instrumental situations especially clear.

The simplicity and domain-generality of this classification should not lead to the conclusion that these emotions emerged from some abstract principles. Far from it. They were shaped by actual experiences that increased or decreased specific reproductive resources that changed gene frequencies in future generations. They do, however, reflect a general tendency of the organism to value certain things, to seek them and to try to avoid losing them. This approach offers special advantages for mental health clinicians whose patients are seeking enormously diverse goals in life. Yes, most of them want status and 
Table 1. The instrumental emotions

\begin{tabular}{llll}
\hline Situation & Before & After & $\begin{array}{l}\text { Alternative } \\
\text { outcome }\end{array}$ \\
\hline $\begin{array}{l}\text { Gain } \\
\text { Physical } \\
\text { Social }\end{array}$ & $\begin{array}{l}\text { Desire } \\
\text { Hope }\end{array}$ & $\begin{array}{l}\text { Pleasure } \\
\text { Happiness }\end{array}$ & (Disappointment) \\
$\begin{array}{l}\text { Loss } \\
\text { Physical }\end{array}$ & Fear & Pain & (Relief) \\
Social & Anxiety & Sadness & \\
\hline
\end{tabular}

money and mates and children, but the ratios differ vastly, and the individual humans are so diverse that their goals have often been described as unique. One person seeks to be good in all actions, another to get on the Broadway stage, another to be loved by her children, another to have a beautiful garden, another to achieve spiritual salvation, another to be feared by people, another to have many lovers, another to know everything it is possible to know about the lives of ants. To understand a person, we must start by understanding what goals they are seeking, and how. Whatever the goal, progress or failure, gain or loss are likely to be reflected in the instrumental emotions in Table 1 above. In this way, an evolutionary approach helps us to understand people in their uniqueness.

Experience with different specific resources has shaped subtypes of each of these global instrumental emotions. Most broadly, we readily differentiate the potential or actual gain or loss of physical resources (desire, pleasure, fear, pain) from resources that are less tangible and more social (hope, happiness, anxiety, sadness). More specifically, there are subtypes of each that correspond to the nature of the resource at issue and the kind of situation. For instance, the proverbial breath of the sabre-toothed tiger will arouse the special kind of fear called panic, and the cut of those teeth will cause pain, while the presence of a tiger steak will arouse the special kind of desire we call appetite, the satisfaction of which gives the pleasure of satiation. On the less tangible side, hope of success in an examination can resolve into happiness or disappointment depending on the outcome, while anxiety about possibly having insulted a friend can result in sadness or relief.

The subtypes of anxiety are especially instructive. The DSM system, resolutely atheoretical, distinguishes general anxiety from social phobia, panic disorder, agoraphobia, specific object phobias, blood phobias and hypochondriasis. Do these categories correspond, as predicted, to distinct situations that involve losses of specific kinds? Again, this is the topic for an entire paper, but a brief table (Table 2) shows some substantial correspondences (Marks \& Nesse, 1994).

The relationships among these subtypes is illuminated as well. As already emphasized, natural selection may well have partially differentiated them from common precursor states, so that it may be futile to attempt to show either that they are entirely distinct, or that they are all basically the same. The recent discovery that general anxiety and major depression share a common genetic predisposition, which is different from that of panic, is of great clinical importance (Kendler, Heath, Martin \& Eaves, 1987). Such studies of individual differences are, however, a matter separate from the evolutionary origins and 
Table 2. Subtypes of anxiety

\begin{tabular}{ll}
\hline Clinical subtype of anxiety & $\begin{array}{l}\text { Situation in which a related response } \\
\text { might be useful }\end{array}$ \\
\hline Panic & Life-threatening danger \\
Social phobia & Threat to reputation or status \\
Animal phobia & Dangerous small animals \\
Acrophobia & Heights \\
Agoraphobia & An environment with dangerous predators \\
Hypochondriasis & Threat to health \\
Blood phobia & Injury \\
General anxiety & General dangers \\
\hline
\end{tabular}

functions of the normal capacities for anxiety and mood. For instance, a gene can eventually result in both heart failure and kidney failure (perhaps via effects on atherosclerosis), but this obviously does not mean that the heart and the kidney are basically the same.

\section{The utility of negative emotions}

For clinicians, the single most important conclusion from an evolutionary view of emotions is the recognition that negative emotions are often useful. Anxiety, regret and sadness must have utility, or they would not exist. Pain offers a fine analogy. We experience pain during tissue damage-a bad situation indeed, one that should be escaped now, and avoided in the future. But although the situation is bad for us, the pain is useful. Individuals with a genetic lack of capacity for pain typically incur cumulative injuries and die by their early 30s (Melzack, 1973). Fever offers another example. Fever is not the problem itself, it is the body's adaptive response to infection (Kluger, 1979). We know that fever is an adaptation, and a subtly regulated one, but because we can so readily take aspirin and feel better without obvious complications, it is easy to slip into thinking that fever, even if useful, is more trouble than is it worth. Indeed, we do not yet know if it is wise to block the fever during influenza, but we do know that the capacity for fever is an adaptation.

The confusion in the medical clinic about defensive responses is magnified in the mental health clinic (Dixon, 1998). For instance, most clinicians acknowledge the potential utility of anxiety, but because anxiety is so prevalent and so often obviously deleterious, it is easy to think that it is a disease instead of one of the body's protective mechanisms. The relief and improved functioning that follow pharmacological blockade of anxiety furthers the illusion that anxiety itself is the problem. If anxiety and fever are useful, how can interfering with their functions cause so few untoward effects? First, the body has redundant defence mechanisms so blocking one of them may cause few problems. Second, our environment is safer now than it was when we evolved. Third, natural selection shaped the regulation mechanisms for maximal reproductive success, not for peace and happiness. So, these mechanisms will arouse a response like anxiety whenever the protection multiplied by the likelihood of harm is greater than the cost of the response. If the cost is low, the defence will, even when the system is operating 
normally, be expressed in an manner that seems too often, too early, too intense and too prolonged, but that is, in fact, near optimal. This has been called the 'smoke detector principle', after the frequent but normal and necessary false alarms from those devices (Nesse \& Williams, 1995).

From this perspective, there are two kinds of anxiety disorders, those in which anxiety is expressed excessively and those in which it is expressed insufficiently. Can it be abnormal to have too little anxiety? Yes, in exactly the same way that there can be insufficient pain or an insufficient immune response, and with equally devastating consequences. Patients with insufficient anxiety do not, however, come to therapists to have their anxiety increased, even when their incautious actions result in accidents, losses of jobs and relationships and drug addiction. And pharmaceutical companies have yet to market an agent designed to increase deficient anxiety to normal levels (although an agent that increases caution without increasing subjective anxiety would have a huge market, with probable ability to prevent relapse into drug addiction, among other benefits). Thus, the disorders we see in clinic are skewed to those people who suffer from excessive anxiety. The question of why there is such marked genetic variation in the tendency to experience anxiety is important, but a topic separate from the issues addressed in this paper. It could merely be that deleterious mutations accumulate faster than they can be removed, or that alleles drift to substantial frequencies, but it seems more likely that our ancestors existed in environments with a wide range of levels of danger, and this variation has prevented natural selection from narrowing the normal range of susceptibility to anxiety to anywhere near the degree it has narrowed body temperature or, for that matter, even stature. While the issues cannot be addressed here in detail, it should be noted that it is important, and will soon be possible to find out, whether people with anxiety disorders are merely at the tail of a normal distribution, or if they have distinct genetic sequences. Even if anxiety disorders are associated with distinct genes, this will not tell us whether those genes are mere mutations not yet selected out, or if they have been selected for despite the anxiety they cause.

\section{Sadness and low mood}

Sadness and low mood are more difficult to understand than anxiety. While it is easy to see that anxiety may help someone to avoid a looming danger, it is harder to see how a special state could be useful after a loss has occurred. The loss has already happened, so what good is a special emotion of sadness? While we do not yet know the exact answer, a general explanation is that after a loss, a special state can prevent further similar losses and can motivate reassessment of adaptive strategies in the light of the loss (N esse, 1991).

Depending on the nature of the loss, there are many specific ways in which a special state might increase fitness after a loss.

(1) Prevent further immediate losses. If a child has been lost to high waves, or a cow to wolves, or food to scavengers, immediate action may prevent additional losses.

(2) Recover the lost object if possible. In grief, searching for the lost loved one seems useless in a modern society, but in the ancestral environment, such searching might often have paid off. In other situations where the resource might be recovered, motivation of persistent searching may also be adaptive. 
(3) Avoid situations and actions that may have been associated with the loss. Presumably the situation is dangerous or otherwise undesirable. Even if the situation or place was not obviously the cause of the loss, avoidance may still, on average, be useful. People who experience severe danger, for instance, reliably avoid the place where it happened. Superstitions in such instances can be functional.

(4) Try to understand the cause of the loss, especially if the threat may recur and understanding it might prevent future loss. The rumination observed in people who have experienced severe losses often seems excessive or even senseless. But if on some occasions such cognition results in behaviour that prevents future losses, the mechanism may, overall, be worth it. Women ruminate substantially more than men and this seems to explain much of the sex difference in susceptibility to depression (NolenHoeksema \& Morrow, 1993). Do women have more resources to lose, and is their thinking about possible losses more productive than that of men? Or do they just lack power (Wenegrat, 1995)? Searching for information about the causes of a loss, and monitoring for cues that the same untoward event may be looming, can cause symptoms of a generalized anxiety disorder, but such symptoms may protect against future losses.

Half of the people with a panic disorder go on to develop depression, and people who are depressed experience concurrent anxiety, but people with severe depression rarely go on to develop pure panic disorder (Angst, Vollrath, Merikangas \& Ernst, 1990). Such overlap, arising from diagnostic canons that separate anxiety and depression, has given rise to a thriving research industry to account for co-morbidity (Maser \& Cloninger, 1990). Much of the co-morbidity probably arises from personality and genetic factors. The genes that predispose to generalized anxiety disorder seem to be the same as those that predispose to depression (Kendler et al., 1987). To explain within-subject changes, however, the functional significance of anxiety and depression may help. If people experience anxiety in anticipation of a loss, and then it occurs and causes sadness, this would explain much co-morbidity. More generally, life situations that involve loss usually also involve risks, and vice versa.

(5) Reassess major life strategies to determine if they need to change because of the loss. Loss of territory, a friend, a spouse, skills, appearance or a role in a group all will require many other changes and careful consideration of alternatives (Gut, 1989).

(6) Replace the lost resource if possible. This often is the best response to a loss, but before acting, an assessment of the costs and alternatives is essential, especially if one is likely to suffer another similar loss. Men and women whose spouses leave them often are wary of starting new relationships, and they may choose partners who may seem less desirable, perhaps to avoid another loss.

(7) Get help from kin. In times of need, kin often will offer extra help, so communicating one's loss is therefore useful.

(8) Warn kin about the danger to help them avoid the same loss.

(9) If the loss is a loss of status, then withdraw or submit, in order to avoid attacks. Several theorists have emphasized the similarity of depression to the behaviours of males defeated in hierarchy competitions (Gardner, 1982; Price, Sloman, Gardner, Gilbert \& Rohde, 1994). Especially in conjunction with data showing consistent plasma serotonin changes in such situations (Raleigh, McGuire, Brammer, Pollack \& Yuwiler, 1991), it seems likely that a special kind of response is available for situations 
characterized by a fall in a status hierarchy. Whether such responses offer a global model for low mood, and whether low mood and submission arise from similar or different brain mechanisms are important open questions.

(10) Offer reparations or flagellate the self, if that might help to reconcile a lost relationship. The apparently puzzling tendency of guilty people to punish themselves makes sense in a reciprocity context. If a person takes advantage of a relationship, but then realizes that the relationship is more valuable than the advantage gained, then reparations must be offered. If they are not accepted, the guilty person must then deprive him or herself of more than the resources gained, in order to convince the injured party to re-establish the relationship.

\section{Depression}

So far, we have discussed only the emotion of sadness, not the longer lasting and more global state of low mood state we call depression. Can depression itself be useful? Several other papers in this issue offer sophisticated specific proposals (Gilbert, 1998; McGuire \& Troisi, 1998) that build on previous work (Gilbert, 1989, 1992; Wenegrat, 1990), so I will not review them in any detail except to say that their emphasis on the special roles of high and low mood in negotiating social hierarchies, and the understanding of these normal functions, seems likely to give us a much deeper understanding of depression and mania. Here, I will restrict the discussion to a more global view of mood, one that combines an evolutionary perspective with what we know about the characteristics of depression and the cues that induce and relieve it, in order to arrive at a hypothesis about the situations in which it might conceivably be useful.

Certainly there is agreement that depression often follows major negative life-events, and that most of these are losses, not threats, and, even more specifically, loss of reputation or humiliation are especially common precipitants (Brown, Harris \& Hepworth, 1995). But when is it useful to do nothing? The global answer must be 'in situations where there is nothing useful to do'. There are many such situations, winter and night being two that recur and have shaped special states, hibernation and sleep, respectively (Engle \& Schmale, 1972). But these states are cyclic and affect all members of a species in similar ways. Depression, by contrast, does not arise from the global environment (except perhaps for seasonal affective disorder: Schlager, Schwartz \& Bromet, 1993) but from the individual's social environment. Are there situations when it is optimal for an individual to do nothing? Yes-when all of a person's available options have more costs than benefits. Such situations are difficult to recognize because the social ecosystem is invisible, with its roles, relationships, alliances and hierarchies hidden in tones of voice, glances and subtle choices of word. In the most mild version, such situations are characterized by a person having viable endeavours and strategies, but some impediment that means a major life goal will not be reached. For instance, every therapist has seen a married and employed person whose goal is to have a family, but who is infertile and so far unwilling to accept that fact. In a more severe situation, a major life enterprise is failing, usually a job or a marriage. Finally, there are the unfortunate people with no kin and no viable enterprises at all.

I have long observed that many depressed people are persisting at enterprises that will never succeed. Depression often begins when a person tacitly realizes that a major 
enterprise will never work. Many of my patients begin to recover from depression as soon as they give up on a major life enterprise, even if that giving up will result in major hardship. Bibring (1953) observed nearly the same phenomenon, although he couched it in terms of the mismatch of the ego ideal with reality. Klinger, in a seminal 1975 paper, developed the theory that depression arises when a person fails to 'disengage' from a failing major life endeavour and depression is useful if motivating the disengagement. The theory was taken further by Brickman (1987), in studies of 'commitment', and, more recently, by Carver \& Scheier's (1990) studies of control theory, where depression is also seen as a motivator to disengage from a commitment that is not paying off. Price and colleagues have observed the enormous importance of 'yielding' in relieving depression that arises from status conflicts (Price \& Sloman, 1987; Sloman, Price, Gilbert \& Gardner, 1994).

This relatively well-developed theory about the role of depression in facilitating disengagement has had surprisingly little impact in psychiatry and almost no bridges to behavioural ecology except those provided by Price, Gilbert and colleagues. But when viewed in an evolutionary perspective, the 'disengagement' theory is as biological as can be. Every organism must regulate its expenditures of resources and effort both in time and direction, so as to get maximal benefit. In behavioural ecology, the duration of feeding at a given site before moving on to another site is well understood, and theoretical models make remarkably accurate predictions of actual animal behaviour (Stephens \& Krebs, 1986). Ladybird beetles, for instance, experience a declining rate of return when feeding on an aphid. How long should a ladybird continue before stopping to search for another aphid? It depends on how long the average search time is. The optimal strategy is to feed on one aphid until the rate of return declines below that of the average over a longer time of finding and feeding on several aphids, and that is exactly what they do (A lexander, 1996). But they do not experience a period of inhibition at the end of feeding, they just go on to find another aphid. Bumblebee foraging is another example (Heinrich, 1979). The bee continues to feed on a given flower until the rate of return declines below the average available; this is the optimal strategy according to the marginal value theorem (Charnov, 1976). Human foraging is similar. People stay at one site until the rate of return declines below the average, and then they move on, as anyone who has ever picked raspberries knows, and as confirmed by quantitative studies (Smith, 1985).

After a loss, or when a major life enterprise is failing, it is fairly easy to imagine how stepping back and assessing one's plans could be useful, a proposal developed in particular depth by Emmy Gut (Gut, 1989). This could explain the withdrawal and rumination associated with depression. But what about the negative thinking, the self-criticism, the hopelessness and lack of initiative? If things are not working, wouldn't the best thing be to get energized and confident in order to go out and find an alternative? Such hopelessness and helplessness seem so maladaptive that countering them has become a whole therapeutic enterprise (Alloy \& A bramson, 1982). This, it seems to me, is the core paradox of depression, one that makes it all too easy to assume that depression is al ways pathological. At the very time when action and confidence would seem most needed, people withdraw, feel inadequate and cannot even see other alternatives.

So, is depression for motivating change or stasis? The question cannot be answered because it is miscast. If instead of trying to specify the function of depression, we stick close to the situation that may have shaped it, a possible explanation reveals itself. If a huge 
life enterprise is failing (a long-term marriage or job or relationship or cherished goal), then it may not be wise to disengage quickly. In fact, because of the high entry costs for most such enterprises, and the uncertainty, costs and risks involved in finding an alternative, disengaging too soon may be very unwise, especially if there is any chance of the enterprise recovering. From this perspective, the negative thinking and self-criticism associated with depression may be an integral part of an adaptive syndrome. In the situation where a major life enterprise is failing but there is no ready alternative, it may be adaptive to both withdraw effort from the failing enterprise, and to simultaneously inhibit investment in something new. This period ofwithdrawal and inability to move on gives the enterprise a chance to recover. If it is a relationship, the low mood signals the likelihood of a coming rupture of the relationship so that the partner has a chance to take action to repair the situation. If the enterprise continues to fail, the pain of depression motivates moving on despite the costs and risks. As every clinician knows, depression is not a calm state, like sleep or hibernation, that merely conserves energy, but an active anguished state, with anxiety and rumination even when the depressive has psychomotor retardation.

Why don't people move on? Why do they persist in jobs and relationships that will never improve, unable to disengage, with depression escal ating steadily as its objective is not achieved? Deep answers require knowing the individual, but a checklist is very valuable in the clinic. Exploring these reasons for persisting often give insight into why a person is living as he or she is. At the least, it gives the therapist more empathy for the person's unwillingness to change.

1. Attachment: Emotional connection with a person.

2. A mbition: Unwillingness to give up a status goal.

3. Anxiety: Fear of making changes.

4. Absence of alternatives: Sometimes there really are few alternatives.

5. Social pressure: The social group may demand persistence.

6. Moral beliefs: One's own conscience may demand persistence.

The above comments offer only a sketch of a broad evolutionary approach to depression, and should not be taken as anything but suggestions. Depression may well be a disease pure and simple, with no adaptive significance. This possibility is supported by recent research showing that certain people are genetically much more susceptible to depression than others, and that beyond the third episode, life-events seem to have little influence on the onset of depression (Frank et al., 1996). The possibility that depression is an adaptation should not lead any reader to conclude that treatment should be withheld. Antidepressants, even if they do sometimes disrupt normal states, are modern miracles just as anaesthetics were in the previous century. It is worth noting, however, that the efficacy of antidepressants does not demonstrate that depression is caused by a brain state except in the superficial sense that every behaviour and emotion has a brain mechanism. In fact, the finding that antidepressants act via multiple brain mechanisms suggests that there may be many links in the brain systems that normally express low mood, breaking any one of which might disrupt the depression. Even some of the genetic variation in susceptibility to depression may reflect a normal distribution, just as some people are especially prone to get a fever, while others hardly do. Manic depression is, of course, a separate condition, with powerful and distinct genetic causation. Here the interesting 
evolutionary question is different-whether the genes that predispose to manic depression give, in some people in some combinations with other genes, a selective advantage (Wilson, 1992; Wilson, 1998).

\section{The social emotions}

The evolution of the social emotions can be understood only in the context of why sociality exists at all. Why are organisms social? There are only a few different kinds of benefits from being near others of the same species (Alexander, 1979; Trivers, 1985). First, there are the benefits of the selfish herd. Staying close to the group offers warning and often protection against predators, for birds, minnows and humans. In this situation, no relationship is necessary to get the benefit, just one's presence in the group, so this aspect of sociality will not be discussed further here. Second, there are situations of coercion or deception, as when black ants capture red ant slaves, or ant-mimics enter an ant nest. Such coercion often intersects with hierarchical relationships and will be discussed in that context. Third, there is kin selection, the means by which natural selection shapes tendencies that decrease individual reproductive success but give benefits to genes identical to one's own that reside in one's children and relatives. Fourth, there are benefits from the exchange of favours, usually called reciprocity. Within reciprocity there is a world of complexity. Hierarchy, in kin as well as reciprocity relationships, has been well explored, but its applications to psychopathology are just now being recognized (Gilbert, 1989). Less well explored are the ways in which threats and promises create a virtual world of expectations that have a profound impact on social actions and, ultimately, on gene frequencies.

\section{Kin selection, attachment and parent-offspring conflict}

The social bonds between parent a child, and the emotions that mediate them, are products of kin selection. Helping one's children is so natural it is worth pausing for a moment to note that effort invested in caring for children is effort that cannot be spent on gathering resources for oneself or mate competition or mating. In short, taking care of children results in earlier death and fewer additional children. But humans, and parents in many other species, do take care of offspring because they share their genes (Bailey \& Wood, 1998). In Hamilton's terms, the coefficient of relationship with one's children is 0.5 , so a gene will increase in frequency if it codes for an action that gives a benefit to offspring that is more than twice the cost to self (Cronin, 1993; Hamilton, 1964). There is, of course, no one-to-one correspondence between genes and behaviours, but this simplification makes the idea clear. One level up, in the trade offs studied by behavioural ecologists, effort spent on parenting inevitably decreases somatic and mating effort (Krebs \& Davies, 1997). This very simple principle proves revealing for many clinical cases. One person spends almost all his life effort on getting money-somatic effort in the terminology of behavioural ecology. Another puts parenting first, and decreases mating and somatic effort. Still another person spends most of life's energy on mate attraction. Such extremes are often pathological, and at the root of what we call character pathology. A more normal pattern is to allocate effort among all the tasks of life, in a 
sequence that first seeks somatic resources, then mating, then parenting. Many modern people seem to be under the illusion that no trade offs are required. It would be interesting to learn more about the origins of this illusion, and its effects, and its relationship to the personality disorders.

Bowlby first brought a biological perspective to the phenomenon of child-parent relationships with the concept of attachment (Bowlby, 1969). At first the idea was based on simple proximity. Offspring that stay close to their parents are protected from predation, so there is selection for motivation to stay close to parents, and motives in the parent to keep the offspring close and safe. They cry of a baby is useful because it arouses emotional distress in the parents (Barr, 1990).

The apparently obvious problems that resulted from disruptions of attachment have led the field of attachment research to emphasize the ideal situation of 'secure' attachment, and to view 'anxious' and 'ambivalent' patterns of attachment as abnormal (Ainsworth, Blehar, Waters \& Wall, 1978). A more rigorous evolutionary view suggests, however, that the variations in attachment style may be a facultative adaptation by which infants use whatever tactics are likely to work to influence their parents (Chisholm, 1996). Our ideal of perfectly caring parents who are able to meet all of a baby's needs is wonderfully common in modern times, but the exigencies of the ancestral environment often left parents making hard choices about where limited efforts or food supplies should go. Anxious and ambivalent attachment may be strategies babies use to deal with these situations. In a related vein, crying for no apparent reason gets a baby picked up, where it is safe from predators.

The inevitability of conflicts between parents and offspring has been sketched best by Trivers (1974), who uses weaning conflicts as the exemplar. While the genetic interests of the parent and offspring are congruent for a time, the parent is related to the offspring by a coefficient of relationship of 0.5 , while the offspring is, obviously, related to itself, gene by gene. When the growth of the baby is sufficient, it becomes in the mother's interests to have another baby, while it is in the baby's interests to continue nursing. The weaning conflict, therefore, is a constant across the mammals. It does not reflect pathology and it is not a problem to be solved, but a conflict to be dealt with. Imaginative psychoanalytic theories about this phase of development remarkably reflect the actual conflict at issue (Klein, 1988), but they do not yet make use of the evolutionary explanation for the conflict and they do not recognize that it does not represent pathology. Even phenomena as mundane as spitting up may arise from this source. The amount of milk a mother makes depends on how much a baby drinks. So, a baby that drinks more than it can use manipulates the mother to make extra milk, ensuring a sufficient supply, al beit at the cost of some waste of the mother's caloric reserves.

How does the baby manipulate the parent! As Trivers has observed, the infant cannot force the parent to provide more than it wants to, so it must use deception. And the best kind of deception is to act younger than it really is. In short, to regress. The parent's response to this regression is predictably ambival ent, irritable and suspicious. Therapists react the same way to regression, and probably for the same reasons (Slavin \& Kriegman, 1992). The evolutionary origins of regression as a strategy are an unappreciated foundation for psychodynamics, one that can explain many emotions in the therapeutic situation (Nesse, 1990b). 


\section{Social emotions}

Many authors have noted that for humans, the main reproductive resources are social resources, and much of life is spent in social efforts (Alexander, 1974; Cronin, 1993; Humphrey, 1976). That solitary confinement is worse even than most prisons, is a telling fact about human nature. While much social life arises from the genes we share with our kin, social exchange based on reciprocity is equally important (Axelrod, 1984). Trading favours is the essence of public social life and gives major advantages, but it exposes the participant to the danger that the partner will not return the favour, so almost (more about this crucial qualifier later) every social interaction requires subtle decisions. This core social situation is modelled using the Prisoner's Dilemma, a two-person game with repeated plays in which each participant either cooperates or defects. The maximum mutual long-term gain comes from cooperating on each turn (say, three points each for a total of six), but a larger reward (say, five points) goes to an individual who defects when the other cooperates (and receives nothing). If both defect, both get some smaller number of points (say, one). In the usual diagram form, the four outcomes are:

Other cooperates

Other defects

\begin{tabular}{lll}
\hline Self cooperates & 3 to Self, 3 to Other & 0 to Self, 5 to Other \\
Self defects & 5 to Self, 0 to Other & 1 to Self, 1 to Other \\
\hline
\end{tabular}

If dealing effectively with these four situations has indeed been crucial to fitness, then we can predict that there will be an emotional state that corresponds to each. As the diagram below shows (inspired by Trivers, 1971, 1981), there is a remarkable correspondence between these situations and specific emotions.

Other cooperates

Other defects

Self cooperates

Friendship, trust

Before Suspicion

After: Anger

Self defects

efore Anxiety

Hatred, mistrust, rejection

After: Guilt

This simple classification offers many insights into pathological emotions. Trust grows slowly, and with increasingly risky exchanges, because of the risk of the other defecting. When the balance of payments in an untested relationship becomes severely unequal, the risk is high that the one with more resources will defect, an outcome that might have been prevented if the balance had been kept more equal. People who are too quickly excessively generous may find that they attract exploiters who then defect. Conversely, suspiciousness in response to excess generosity is justified, since it often is a manipulation to set up an opportunity for profitable defection. In general, suspiciousness is useful when it detects and prevents a possible defection, or when it prevents further investment in a relationship that makes one vulnerable to exploitation. In response to exploitation, some people learn different strategies, while others get a perverse pride at being morally 
superior to those who take advantage of them, a strategy that lands many in the therapist's office where the same cycle is usually played out in the transference.

Anger, in this perspective, is aroused when another person defects from an obligation. The anger signals that the defection is unacceptable and reparations are needed if the relationship is to continue. It suggests that aggression may escalate to spiteful harm to the defector. Expression of guilt by the defector is the first step towards repair of the relationship, but a major defection may also require reparations, that is, giving up any benefits that came from the defection. If resources to make amends are not available, selfflagellation is another honest signal of the wish to continue the relationship. As such, wishes to harm the self are not always pathological, but may be useful signals in some instances, an insight that is crucial in some clinical cases.

Anxiety, of the nagging ill-defined sort, is, just as Freud said, often a result of an unacceptable unconscious impulse. By moving thoughts and behaviour away from the impulse to defect, the person is protected from the social dangers that would follow. After defecting, some people feel smug, while others are sensitive to what others feel, and experience guilt that motivates introspection, self-blame and acts of expiation and reparation. It also tends to inhibit repetition of the defection. The enormous variation in tendency to defect, apparently based on genetic factors, is of great interest and suggests substantial variation, either within or between human social environments.

Neurotics, in this perspective, respond to defections with increased cooperation. Parents teach their children to be 'good' in this way, but in the wider world, this strategy is too inflexible and must be paired with a willingness to leave a relationship that is unsatisfactory. The instructions to cooperate may be in the parents' best interests to prevent sibs from harming each other, a strategy that adolescents must change when they enter the wider world (Slavin, 1990; Trivers, 1981). Anger is, ultimately, a threat to leave a relationship if the other will not change. This is extremely difficult for people who are insecure, or who think that they have no alternatives, or who, like some young mothers, have few alternatives. They cannot leave and they cannot fight, so they try harder and hard to cooperate. Often this works. However, when they are abused yet more, this strategy must change, usually in a crisis that involves anxiety, depression, anger and often self-destructive behaviour and interventions by mental health professionals. Therapists have long known that life crises are opportunities to change major life strategies, but the emotions of those situations are often the engines of change. Prior to the change, the neurotic most often is persisting with an escalating strategy of cooperation, manipulation, complaining and helplessness that leads reliably to depression.

\section{Conflict, commitment and the utility of irrational emotions}

Many social interactions are based, not on reciprocity, but on conflict. In the simplest example, two parties struggle over a resource, and whatever one gains, the other loses. This is the essence of a zero sum game (Sigmund, 1993). While the struggle is sometimes settled by the stronger party taking the resource, far more often there is a negotiation based on threats and promises. It will often be in the stronger party's interest to settle for only part of a resource if that will avoid the effort and risk of a fight. It will often be in the weaker party's interest to accept only a fraction of the resource if the alternative is getting none. The outcome of these factors makes dominance and submission an evolutionarily 
stable pair of strategies (Maynard Smith, 1982). Taking a submissive position is not optimal, but it is better than being excluded from the social network. Dominating completely may be desirable, but is rarely worth the costs. The emotions of ambition, pride, humiliation and resentment were likely formed in this crucible.

The most intense social emotions are characterized by threats and promises, conflict and love. Why are these emotions so 'emotional'? An emotional state, in this special context, means that the individual's behaviour is unpredictable, and that the individual may take actions that seem irrational, such as fighting with someone bigger. Game theory offers two possible explanations.

First, in many games, the optimal move depends on what the other will do, and if the other knows your move in advance, you are at a disadvantage. So an optimal strategy requires taking alternative actions according to a strict proportion, but with a completely random pattern (Maynard Smith, 1982). The erratic nature of human behaviour under the sway of certain emotions, especially anger, is entirely expected. Just as a fly that walks randomly on a wall is safer than one that uses any predictable pattern, a human with unpredictable responses in a confrontation has advantages over a person whose responses can be accurately predicted. In short, the erratic nature of emotional behaviour may be essential to its adaptive function.

Second, is an explanation for why emotion seems to induce behaviours that are rash and lead to danger and loss. Fighting a bully is a classic example. In such cases, a rash action leads to immediate losses that make the action seem senseless. In the long run, however, such action often gives long-term benefits. Anger that motivates such behaviour essentially overwhelms the usual decision-making process and leads to behaviour that is 'irrational' in the short term, but often advantageous in the long term. The perspective is, paradoxically, the exact opposite of the common expectation that emotions make people do things that are 'shortsighted'. The emotions often know more than we do. The benefits may be hard to identify because they so often involve reputation. Fighting the bully results in a beating, but subsequently the bully picks on someone el se first. Falling in love constrains one's options, but it can result in a better mate and the benefits of a deep mutual relationship that are not otherwise possible.

Many of the benefits of emotion come from their ability to establish commitments that are guarantors of threats and promises (Frank, 1988; Hirshleifer, 1978; Schelling, 1960). Carrying out any threat requires a sacrifice, and some hurt the self as much or more than the other. Whether the threat is to leave a boring movie with or without one's partner, to leave a marriage, or to respond to any nuclear attack by destroying the entire world, the goal is to use the threat to get the other to comply with a demand, without having to carry out the threat. Paradoxically, however, such threats work only if they are believed, and they are believed only when it appears to both parties that they will, in fact, be carried out. This is the 'commitment' that is required for a threat to work. It can be guaranteed by turning over the task of carrying it out to another party, by setting in place some system that will automatically carry out the threat, or by setting up contingencies that make it in one's interests to carry it out. From these circumstances comes the paradox that constraining one's own options is often essential to negotiate successfully.

The social emotions establish commitment to carry out a threat in two ways. First, the emotion demonstrates that one's behaviour is not based on rational calculation and that one is willing to behave 'irrationally'. Second, the emotional display establishes a public 
commitment to carry out the threat, thus pledging one's reputation to its enforcement. In ancient Thebes, when Creon declares a murder penalty for anyone who tries to bury the body of Polynices, this threat sets in motion the action of Antigone, whose honour demands that she show respect to her dead brother. She does, and Creon has to carry out a version of his threat, but this unravels the whole social fabric. The problem with threats is that if they are not carried out, reputation is fatally lost, but if they are, other catastrophes supervene. The current brinkmanship in the Middle East illustrates the risk and benefits.

On the positive side, people also gain major advantages if they can demonstrate a commitment to love another person irrespective of the person's objective value: 'In sickness and in health, for richer and poorer'. The emotion of love goes beyond simple trust that arises in a successful reciprocity relationship, to a promise of help even in times when it is unlikely to ever be repaid. Like fighting the bully, this may seem senseless from a short-term view. But people who can successfully engage in loving relationships have a huge evolutionary advantage over other people on several counts. First, they have access to help at those desperate times when it is most needed and is otherwise unavailable. Second, they do not need to waste time keeping close track of social accounts. Finally, they can count on support without having to lobby or make promises or threats. There is a risk to all this, of course-the other person may exploit the relationship, or perhaps even take the resources and leave. To prevent this, people enter loving relationships slowly, and with much testing. Zahavi (1976) has shown how, even in birds, the female provokes and mistreats the courting male systematically. Only when he demonstrates a willingness to put up with this will she agree to mate. Such lover's spats have been attributed to all manner of pyschopathology, but they may arise simply from a natural process that tests the lover's resolve, and rejects those who are not willing to demonstrate a willingness to make considerable sacrifices. If it works, the devotion of true love offers life's most valuable resource.

For many people, however, hopes are dashed again and again. A heavy and plainlooking woman came recently to our clinic and reported that she had been radiantly happy over most of the past year ever since she had finally found a man who loved her deeply. She married him. But she almost immediately detected that she was somehow the object of public ridicule, and eventually discovered that her husband was widely known to be homosexual. When she confronted him, he started teasing her cruelly, and she entered a severe depression. Her ability to commit herself to love may now be permanently impaired. For others, there is no trauma, only a cultural belief that people, including the self, are commodities to be bought and sold at market prices that depend on attractiveness, wealth and status. This view of relationships is fostered by capitalistic societies and reinforced by simplistic evolutionary views of human nature based on reciprocity and cynical views of selfish genes and deception. An evolutionary view does reveal much apparent altriusm as self-serving, and it highlights the utility and ubiquity of deception and defection. But it can also illuminate the origins of human benevolence (Nesse \& Lloyd, 1992). The old truism that love is real, but only if you believe in it, may be accurate, and a paradox crucial for the understanding of patients. When patients say, 'But how can I know that you really care about me if I am paying you', they are expressing a profound anxiety. Resolving this paradox is the crux of much therapy that hopes to demonstrate the possibility of a caring relationship.

The argument here, at base, is that a network of threats and promises is, perhaps even 
more than reciprocity, the essence of a social fabric, and that reproductive success depends on finding ways to establish commitments to carry out these threats and promises. The emotions can become guarantors of threats and promises by their ability to make public declarations of intentions to carry out behaviours that are not, in the short run anyhow, in the person's best interests. People who lack this capacity are impaired. For instance, many people with obsessive-compulsive personality disorder make cold calculations of duties and obligations for themselves and others. They do their duty, and can never quite understand why others seem to want something more. Sociopaths do not even have the feeling for duty, and therefore are consigned to superficial mutually exploitative relationships. Deep human relationships are socially constructed from evolved emotional capacities for subjectivity. People who lack these capacities, or who grow up in situations that lead them to believe that love is not possible, often create their own environments in which love is not possible. Sometimes it is possible, and sometimes it is impossible, to help them see the whole other social world that exists unseen all around them.

\section{Conclusion}

Because an evolutionary perspective on the emotions illuminates their functions and dysfunctions, it offers a foundation on which to build understanding not only of the emotions themselves, but also of the social relationships they arise from and give rise to. The emotions we experience are not the machinery of motivation themselves, but they offer a window into that machinery. They are Darwinian algorithms, shaped by natural selection to maximize reproductive success, not our happiness. Therapists who understand where they came from, and what they are for, will be better able to relieve their patient's suffering.

\section{References}

Ainsworth, M. D., Blehar, M. C., Waters, E. \&Wall, S. (1978). Patterns of Attachment: A Psychological study of the Strange Situation Hillsdale, NJ: Erlbaum.

Alexander, R. D. (1974). The evolution of social behaviour. Annual Review of Systematics 5, 325-383. Alexander, R. D. (1979). Darwinism and Human Affairs Seattle, WA: University of Washington Press. Alexander, R. M. (1996). Optima for Animals. Princeton, NJ: Princeton University Press.

Alloy, L. B. \& Abramson, L. Y. (1982). Learned helplessness, depression, and the illusion of control. Joumal of Personality and Social Psychology 42, 1114- 1126.

Angst, J., Vollrath, M., Merikangas, K. R. \& Ernst, C. (1990). Comorbidity of anxiety and depression in the Zurich cohort study of young adults. In J. D. Maser \& C. R. Cloninger (Eds), Comorbidity of Mood and Anxiety Disorders Washington, DC: American Psychiatric Press.

Axelrod, R. (1984). The Evolution of Cooperation. New York: Basic Books.

Bailey, K. G. \& Wood, H. E. (1998). Evolutionary kinship therapy: Basic principles and treatment implications. British Journal of Medical Psychology, 71, 509-523.

Barr, R. G. (1990). The early crying paradox: A modest proposal. Human Nature, 1, 355-389.

Bibring, E. (1953). The mechanisms of depression. In P. Greenacre (Ed.), Affective Disorders, pp. 13-48. New York: International Universities Press.

Bowlby, J. (1969). Attachment. New York: Basic Books.

Brickman, P. (1987). Commitment, Conflict and Caring. Englewood Cliffs, NJ: Prentice-Hall.

Brown, G. W., Harris, T. 0. \& Hepworth, C. (1995). Loss, humiliation and entrapment among women developing depression A patient and non-patient comparison. Psychological Medicine, 25, 7-21. 
Carver, C. S. \& Scheier, M. F. (1990). Origins and functions of positive and negative affect: A control-process view. Psychological Review, 97, 19-35.

Charnov, E. L. (1976). Optimal foraging: The marginal value theorem. Theoretical and Population Biology, 9, 129-136.

Chisholm, J. (1996). The evolutionary ecology of human attachment organization. Human Nature, 7, I-38.

Cronin, H. (1993). The Ant and the Peacock. London: Cambridge University Press,

Dixon, A. K. (1998). Ethological strategies for defence in animals and humans: Their role in some psychiatric disorders. British Journal of Medical Psychology, 71, 417-445.

Ekman, P. \& Davidson, R. J. (Eds) (1994). The Nature of Emotion: Fundamental Questions. New York: Oxford University Press.

Engel, G. \& Schmale, A. (1972). Conservation-withdrawal: A primary regulatory process for organismic homeostasis. In R. Porter \& J.Night (Eds), Physiology Emotion, and Psychosomatic Illness, vol. 8 (new series), pp. 57-85. Amsterdam: Associated Scientific Publishers.

Frank, E., Tu, X. M., Anderson, B., Reynolds, C. F. 3rd, Karp, J. F., Mayo, A., Ritenour, A. \& Kupfer, D. J. (1996). Effects of positive and negative life events on time to depression onset: An analysis of additivity and timing. Psychological Medicine, 26, 613-624.

Frank, R. H. (1988). Passions Within Reason: The Strategic Role of the Emotions. New York: Norton,

Gardner, R. Jr (1982). Mechanisms in manic-depressive disorder. Archives of General Psychiatry, 39, $1436-1441$.

Gilbert, P. (1989). Human Nature and Suffering. Hove: Erlbaum.

Gilbert, P. (1992). Depression: The Evolution of Powerlessness. New York: Guilford.

Gilbert, P. (1998). Evolutionary psychopathology: Why isn't the mind designed better than it is? British Journal of Medical Psychology, $71,353-373$.

Gut, E. (1989). Productive and Unproductive Depression. New York: Basic Books.

Hamilton, W. D. (1964). The general evolution of social behaviour I and II. Journal of Theoretical Biology, 7, $1-52$.

Heinrich, B. (1979). Bumblebee Economics. Cambridge, MA: Harvard University Press.

Hirshleifer, J. (1978). Competition, cooperation, and conflict in economics and biology. Journal of the American Economic Association, 68, 238-243.

Humphrey, N. K. (1976). The social function of intellect. In P. Bateson \& R Hinde (Eds), Growing Points in Ethology, pp. 303-318. London: Cambridge University Press,

Kendler, K. S., Heath, A. C., Martin, N. G. \& Eaves, L. J. (1987). Symptoms of anxiety and symptoms of depression. Same genes, different environments? Archives of General Psychiatry, 44, 451-457.

Klein, M. (1988). Love, Guilt and Reparation. London: Virago.

Klinger, E. (1975). Consequences of commitment to and disengagement from incentives. Psychological Review, $82,1-25$.

Kluger, M. J. (Ed.) (1979). Fever, its Biology, Evolution, and Function. Princeton, NJ: Princeton University Press.

Krebs, J. R. \& Davies, N. B. (1997). Behavioural Ecology: An Evolutionary Approach, 4th ed. Oxford: Blackwell Science.

McGuire, M. T. \& Troisi, A. (1998). Prevalence differences in depression among males and females: Are there evolutionary explanations? British Journal of Medical Psychology, 71, 479-491.

Marks, I. M. \& Nesse, R. M. (1994) Fear and fitness: An evolutionary analysis of anxiety disorders. Ethology and Sociobiology, 15, 247-261.

Maser, J. \& Cloninger, R. (Eds). (1990). Comorbidity of Mood and Anxiety Disorders. Washington, DC: American Psychiatric Press.

Maynard Smith, J. (1982). Evolution and the Theory of Games. London: Cambridge University Press.

Melzack, R. (1973). The Puzzle of Pain. Harmondsworth: Penguin.

Nesse, R. M. (1990a). Evolutionary explanation of emotions. Human Nature, 1, 261-289.

Nesse. R. M. (1990b). The evolutionary functions of repression and the ego defences. Journal of the American Academy of Psychoanalysis, 18, 260-285.

Nesse, R. M. (1991). What good is feeling bad? The Sciences, Nov-Dec, 30-37.

Nesse, R. M. \& Lloyd, A. T. (1992). The evolution of psychodynamic mechanisms. In J. Barkow, L. Cosmides \&J. Tooby (Eds), The Adapted Mind: Evolutionary Psychology and the Generation of Culture. New York: Oxford University Press.

Nesse, R. M. \& Williams, G. C. (1995). Why We Get Sick: The New Science of Darwinian Medicine. New York: Times Books. 
Nolen-Hoeksema, S. \& Morrow, J. (1993). Effects of rumination and distraction on naturally occurring depressed mood. Cognition and Emotion, 7, 561-570.

Plutchik, R. \& Kellerman, H. (1980). Theories of Emotion, vol. 1 Orlando, FL: Academic Press.

Price, J., Sloman, L., Gardner, R., Gilbert, P. \& Rohde, P. (1994). The social competition hypothesis of depression. British Journal of Psychiatry, 164, 309-3 15.

Price, J, \& Sloman, L. (1987). Depression as yielding behaviour: An animal model based on SchyelderupEbbe's pecking order. Ethology and Socidbiology, 8, 85s-98s.

Raleigh, M., McGuire, M., Brammer, G., Pollack, D. \& Yuwiler, A. (1991). Serotonergic mechanisms promote dominance acquisition in adult male vervet monkeys. Brain Research, 559, 181-190.

Schelling, T. C. (1960). The Strategy of Conflic. Cambridge, MA: Harvard University Press.

Schlager, D., Schwartz, J. E. \& Bromet, E. J. (1993). Seasonal variations of current symptoms in a healthy population. British Journal of Psychiatry, 163, 322-326.

Sigmund, K. (1993). Games of Life New York: Oxford University Press.

Slavin, M. (1990). Toward a new paradigm for psychoanalysis: An evolutionary biological perspective on the classical-relational dialectic. Psychoanalytic Psychology, 7, (Suppl.), 5-31.

Slavin, M. \& Kriegman, D. (1992). The Adaptive Design of the Human Psyche Psychoanalysis, Evohtionary Biology, and the Therapeutic Process. New York: Guilford.

Sloman, L., Price, J., Gilbert, P. \& Gardner, R. (1994). Adaptive function of depression: Psychotherapeutic implications. American Journal of Psychotherapy, 48, 1- 16.

Smith, E. A. (1985). Inuit foraging groups: Some simple models incorporating conflicts of interest, relatedness, and central place sharing. Ethology and Sociobiology, 6, 27-47.

Stephens, D. W. \& Krebs, J. R. (1986). Foraging Theory. Princeton, NJ: Princeton University Press.

Tooby, J. \& Cosmides, L. (1990). The past explains the present: Emotional adaptations and the structure of ancestral environments. Ethology and Sociobiology, 11, 375-424.

Trivers, R. L. (1985). Social Evolution. Menlo Park, CA: Benjamin/Cummings.

Trivers, R. L. (1971). The evolution of reciprocal altriusm. Quarterly Review of Biology, 46, 35-57.

Trivers, R. L. (1974). Parent-offspring conflict. American Zoologut, 14, 249-264.

Trivers, R. L. (1981). Sociobiology and politics. In E. White (Ed.), Sociobiology and Human Politics. Toronto: Lexington.

Wenegrat, B. (1990). Sociobiological Psychiatry: A New Conceptual Framework Lexington, MS: Lexington.

Wenegrat, B. (1995). Illness and Power. New York: New York University Press.

Williams, G. C. (1966). Adaptation and Natural Section: A Critique of Some Current Evolutionary Thaught

Princeton, NJ: Princeton University Press.

Wilson, D. R. (1992). Evolutionary epidemiology. Ada Biotbeoretica, 40, 187-189.

Wilson, D. R. (1998). Evolutionary epidemiology and manic depression. British Journal of Medical Psychology, 71, 375-395.

Zahavi, A. (1976). The testing of a bond. Animal Behaviour, 25, 246-247. 